\title{
Crystal structure, DFT calculations and evaluation of 2-(2-(3,4-dimethoxyphenyl) ethyl)isoindoline-1,3-dione as AChE inhibitor
}

\author{
Erik Andrade-Jorge ${ }^{1}$, José Bribiesca-Carlos ${ }^{1}$, Francisco J. Martínez-Martínez² , Marvin A. Soriano-Ursúa ${ }^{3}$, \\ Itzia I. Padilla-Martínez ${ }^{4}$ and José G. Trujillo-Ferrara ${ }^{1 *}$ (D)
}

\begin{abstract}
Dioxoisoindolines have been included as a pharmacophore group in diverse drug-like molecules with a wide range of biological activity. Various reports have shown that phthalimide derivatives are potent inhibitors of AChE, a key enzyme involved in the deterioration of the cholinergic system during the development of Alzheimer's disease. In the present study, 2-(2-(3,4-dimethoxyphenyl)ethyl)isoindoline-1,3-dione was synthesized, crystallized and evaluated as an AChE inhibitor. The geometric structure of the crystal and the theoretical compound (from molecular modeling) were analyzed and compared, finding a close correlation. The formation of the $\mathrm{C} 6-\mathrm{H} 6 \ldots \mathrm{O} 19$ interaction could be responsible for the non-negligible out of phenyl plane deviation of the $\mathrm{C} 19$ methoxy group, the $\mathrm{O} 3$ from the carbonyl group lead to $\mathrm{C} 16-\mathrm{H} 16 \cdots \mathrm{O}^{\mathrm{i}}$ intermolecular interactions to furnish $\mathrm{C}(9)$ and $\mathrm{C}(14)$ infinite chains within the $(-40$ $9)$ and $\left(\begin{array}{lll}-3 & 1 & 1\end{array}\right)$ families of planes. Finally, the biological experiments reveal that the isoindoline-1,3-dione exerts a good competitive inhibition on $\mathrm{AChE}(\mathrm{Ki}=0.33-0.93 \mathrm{mM}$; $95 \%$ confidence interval) and has very low acute toxicity $\left(\mathrm{LD}_{50}>1600 \mathrm{mg} / \mathrm{kg}\right)$ compared to the AChE inhibitors currently approved for clinical use.
\end{abstract}

Keywords: AChE inhibitor, Alzheimer's disease, Crystal structure, Isoindoline-1, 3-Dione, Kinetic

\section{Introduction}

Alzheimer's disease (AD) is a progressive neurodegenerative disorder. Since the gradual damage to neurons leads to an irreversible deterioration of memory and learning, the afflicted person is eventually unable to carry out cognitive functions $[1,2]$. AD is the most common form of dementia in the elderly population [3], accounting for $60-80 \%$ of all cases [4-6].

The pathogenesis of $\mathrm{AD}$ involves the accumulation of soluble amyloid- $\beta$ peptide [7], the dysfunction of the cholinergic system, and the deposition of tau neurofibrillary tangles in the brain [8]. These physiological changes lead

\footnotetext{
*Correspondence: jtrujillo@ipn.mx

${ }^{1}$ Laboratorio de Investigación en Bioquímica, Sección de Estudios de Posgrado e Investigación, Escuela Superior de Medicina del Instituto Politécnico Nacional, Plan de San Luis y Díaz Mirón s/n Casco de Santo Tomás, 11340 Mexico City, Mexico

Full list of author information is available at the end of the article
}

to confusion, memory loss, impaired cognitive and emotional function, and finally dementia [9].

The main drug target is acetylcholinesterase (AChE) [8], which hydrolyzes the neurotransmitter acetylcholine (ACh) at cholinergic synapses and thus terminates nerve transmission. Since low levels of this signaling molecule are associated with the development of $\mathrm{AD}$, high levels of the same are considered desirable in patients [10-13].

According to the cholinergic hypothesis, impairments in the cholinergic pathway play a pivotal role in the pathogenesis of $\mathrm{AD}$ [14]. The main mechanism for enhancing the level of ACh is the inhibition of AChE, which is presently the most effective strategy for treating AD. Hence, the current treatments are cholinesterase inhibitors that target $\mathrm{AChE}$ and butyrylcholinesterase (BuChE), and antagonists of $N$-methyl-D-aspartate (NMDA) receptor $[1,2]$.

In addition to depleting Ach (low concentrations), human AChE accelerates the metabolic rate of 
formation of the amyloid- $\beta$ peptide, which exacerbates the clinical progression of $\mathrm{AD}[15,16]$. Other proteins involved in the development of this disease are tau, $\alpha$-synuclein and apoE4, and all of them are regulated by the activity of AChE [17]. AChE inhibitors (AChEIs) are the only type of drug approved for the treatment of AD.

The phthalimide ring (isoindoline-1,3-dione) represents an important privileged substructure in diverse molecules exhibiting neuroprotective agents, antioxidant, antihypertensive activity, etc. [18-20]. Numerous reports have identified phthalimide derivatives as potent inhibitors of AChE [21-24] and BuChE [1,25].

Paneck et al. synthesized and evaluated phthalimide saccharin derivatives, finding one of these to be a selective AChEI that significantly impeded the accumulation of amyloid- $\beta$ [26]. Simoni et al. developed other new compounds with an indole moiety in their structure that are able to simultaneously inhibit AChE and amyloid- $\beta$ aggregation [27].

The pharmacophore isoindoline-1,3-dione is known to interact with great affinity at the peripheral anionic site (PAS) of human AChE. To optimize the interaction with the catalytic active site at the same time, the linker between the radical of the drug and the isoindoline1,3-dione should include an oligomethylene [28].

Hebda et al. described how phthalimide groups interact with the PAS site of AChE. They found that the two carbonyl groups of phthalimide facilitate hydrogen bonding with AChE, and the replacement of phthalimide groups with a heteroaromatic moiety reduces potency [29]. It has also been explained how an electron donating group as a methoxy substituent, particularly in the para position, confers higher potency to the drug. In the case of electron withdrawing groups, such as chlorine or fluorine moieties, the ortho position provides a greater inhibitory effect on AChE [31]. Finally, it was reported how the ability of a ligand to bend (due to alkyl chains) improves its interaction with the anionic and acyl pocket of AChE. Hence, the presence of alkyl chains may be necessary for excellent potency in a competitive or non-competitive inhibitor [30].

Taking into account the above information the compound was design based on the literature, where is described that for good inhibitory effect on AChE the molecule must have an isoindoline group, the presence of 2 carbonyl groups and also the presence of electron donating groups as methoxy moiety, additionally the presences of methylenes are required for good potency. The aim of the current study was to synthesize and crystallize 2-(2-(3,4-dimethoxyphenyl)ethyl)isoindoline-1,3-dione, then compare its molecular X-ray structure with that of the same compound simulated for molecular modeling. Furthermore, its activity as an AChEI was determined in vitro and $\mathrm{ED}_{50}$ in vivo.

\section{Results and discussion Molecular Structure}

The compound 2-(2-(3,4-dimethoxyphenyl)ethyl)isoindoline-1,3-dione (1; Fig. 1) was afforded as colorless triclinic crystals in the space group $\mathrm{P}-1$, with $\mathrm{Z}=2$. The molecular structure is shown in Fig. 2 and selected bond lengths, bond angles and torsion angles are listed in Table 1. Although the mean value of the $\mathrm{N}-\mathrm{CO}$ (1.393(6) $\AA$ ) bond length is longer than the mean value observed in isolated amide group $(\mathrm{N}-\mathrm{CO}=1.325(9) \AA)$, it is within the expected range for imides (1.396(10) $\AA$ ) [31].

The dimethoxyphenyl and isoindoline-1,3-dione rings are almost coplanar with the torsion angles of $-102.4(2)^{\circ}$ for $\mathrm{C} 10-\mathrm{C} 11-\mathrm{C} 12-\mathrm{C} 13$ and $99.0(2)^{\circ}$ for $\mathrm{C} 1-\mathrm{N} 2-\mathrm{C} 10-$ C11. However, the methyl C19 is markedly more twisted than $\mathrm{C} 18$. An angle of $3.8(3)^{\circ}$ was detected for $\mathrm{C} 18-\mathrm{O} 18-$ $\mathrm{C} 14-\mathrm{C} 13$ and $-9.2(3)^{\circ}$ for C19-O19-C15-C16 (Fig. 3) these results were confirmed with the theoretical modeling (Table 1).

\section{Molecular modeling}

The DFT calculations showed that the optimized structure for molecular modeling is very similar to the X-ray crystal structure. According to the statistical analysis, there was no significant difference in bond lengths or bond angles between these two structures (two-tailed Student's $t$-test; $\mathrm{p}<0.05)$. The geometric parameters of the crystal structure and calculations are listed in Table 1. The optimized structure is illustrated in Fig. 4.

\section{Supramolecular structure}

The non-planar arrangement of the C19 methyl may be related to the network arrangement of $\mathbf{1}$ in the crystal. The geometric parameters associated with intermolecular

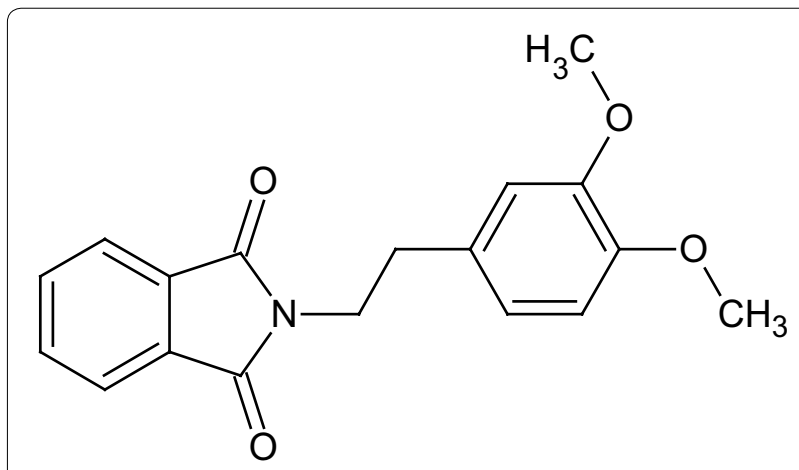

Fig. 1 Molecular structure of 2-(2-(3,4-dimethoxyphenyl)ethyl) isoindoline-1,3-dione (1) 


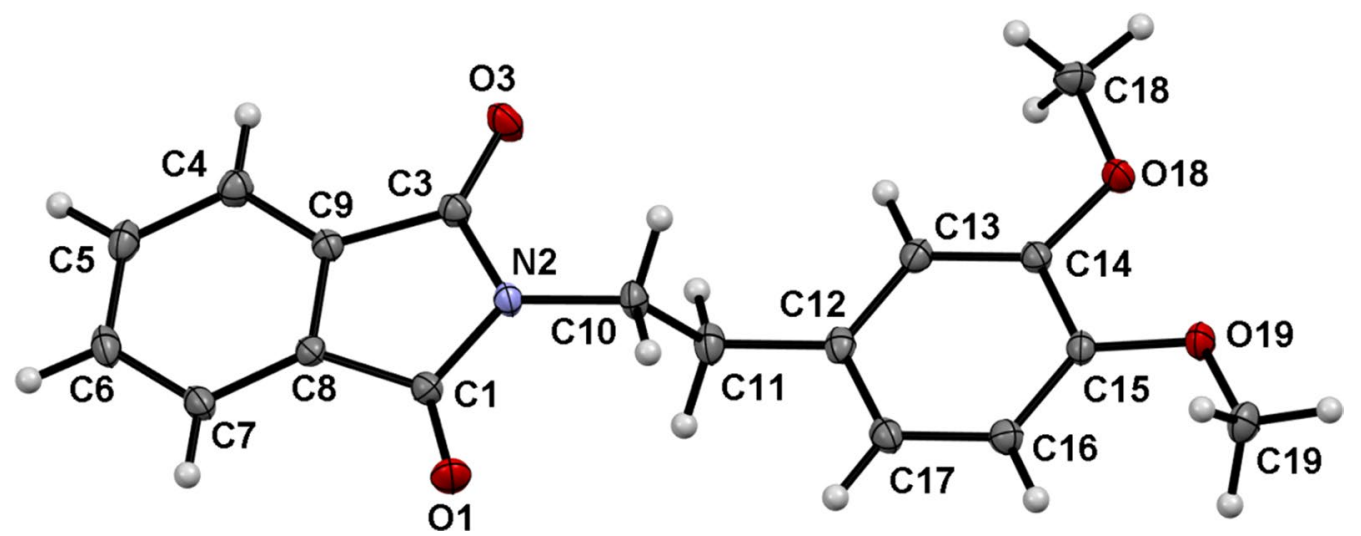

Fig. 2 X-ray molecular structure of 2-(2-(3,4-dimethoxyphenyl)ethyl)isoindoline-1,3-dione (1) with an atom labeling scheme. ORTEP view at the $50 \%$ probability level

Table 1 Comparison between modeled and crystal geometric structures of 1

\begin{tabular}{|c|c|c|c|c|c|}
\hline & Modeled structure & Crystal structure & & Modeled structure & Crystal structure \\
\hline Energy (kJ/mol) & -2760740.50 & & $E_{\text {LUMO }}(\mathrm{kJ} / \mathrm{mol})$ & -549.86 & \\
\hline \multicolumn{6}{|l|}{ Bond lengths $(\AA)$} \\
\hline $\mathrm{O} 1-\mathrm{C} 1$ & 1.239 & $1.208(2)$ & $\mathrm{N} 2-\mathrm{C} 10$ & 1.462 & $1.456(2)$ \\
\hline $\mathrm{O} 3-\mathrm{C} 3$ & 1.239 & $1.211(2)$ & $\mathrm{C} 8-\mathrm{C} 9$ & 1.404 & $1.381(2)$ \\
\hline $\mathrm{N} 2-\mathrm{C} 1$ & 1.410 & $1.397(2)$ & $\mathrm{C} 14-\mathrm{O} 18$ & 1.386 & $1.367(2)$ \\
\hline $\mathrm{N} 2-\mathrm{C} 3$ & 1.409 & $1.389(2)$ & O18-C18 & 1.450 & $1.427(3)$ \\
\hline $\mathrm{C} 1-\mathrm{C} 8$ & 1.489 & $1.489(3)$ & C15-O19 & 1.387 & $1.371(2)$ \\
\hline C3-C9 & 1.489 & $1.484(3)$ & O19-C19 & 1.449 & $1.428(2)$ \\
\hline \multicolumn{6}{|l|}{ Bond angles $\left(^{\circ}\right)$} \\
\hline $\mathrm{C} 9-\mathrm{C} 3-\mathrm{O} 3$ & 129.1 & 129.14(16) & C14-O18-C18 & 118.4 & 116.60(15) \\
\hline $\mathrm{O} 3-\mathrm{C} 3-\mathrm{N} 2$ & 124.9 & $124.64(17)$ & C16-C15-O19 & 124.6 & $124.52(16)$ \\
\hline $\mathrm{C} 3-\mathrm{N} 2-\mathrm{C} 10$ & 123.8 & $123.14(14)$ & C15-O19-C19 & 118.3 & $116.51(15)$ \\
\hline N2-C10-C11 & 112.6 & $111.62(18)$ & O18-C14-C15 & 115.8 & 115.22(16) \\
\hline C13-C14-O18 & 124.4 & $125.17(16)$ & O19-C15-C14 & 116.0 & 116.96(16) \\
\hline \multicolumn{6}{|l|}{ Torsion angles $\left({ }^{\circ}\right)$} \\
\hline $\mathrm{O} 3-\mathrm{C} 3-\mathrm{N} 2-\mathrm{C} 10$ & 1.015 & $-3.0(3)$ & $\mathrm{C} 18-\mathrm{O} 18-\mathrm{C} 14-\mathrm{C} 13$ & 0.271 & $3.8(3)$ \\
\hline $\mathrm{O} 1-\mathrm{C} 1-\mathrm{N} 2-\mathrm{C} 10$ & -0.935 & $1.7(3)$ & C19-O19-C15-C16 & 0.258 & $-9.2(3)$ \\
\hline N2-C10-C11-C12 & 177.174 & 179.44(16) & O18-C14-C15-O19 & 0.038 & $2.1(3)$ \\
\hline C10-C11-C12-C13 & -82.95334 & $-102.4(2)$ & & & \\
\hline
\end{tabular}

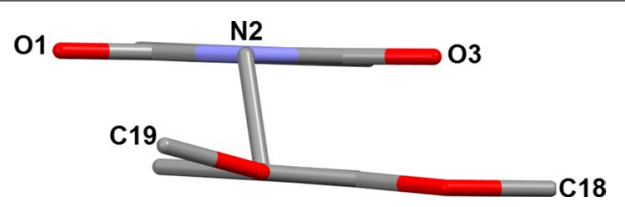

Fig. 3 The molecular structure of $\mathbf{1}$, viewed along the axis of C11$\mathrm{O} 19$ atoms. The hydrogen atoms are not included for the sake of clarity intermolecular interactions are listed in Table 2. The graph set notation is used to describe the intermolecular interactions motifs [32].

The $\mathrm{O} 3$ and $\mathrm{O} 19$ oxygen atoms, from the carbonyl and methoxy groups, lead to $\mathrm{C} 16-\mathrm{H} 16 \cdots \mathrm{O} 3^{\mathrm{i}}$ and $\mathrm{C} 6-$ $\mathrm{H} 6 \cdots \mathrm{O} 19^{\mathrm{ii}}$ intermolecular interactions to furnish $\mathrm{C}(9)$ and $C(14)$ infinite chains within the (-4 09$)$ and (-3 1 1) families of planes, respectively. Both motifs combined 


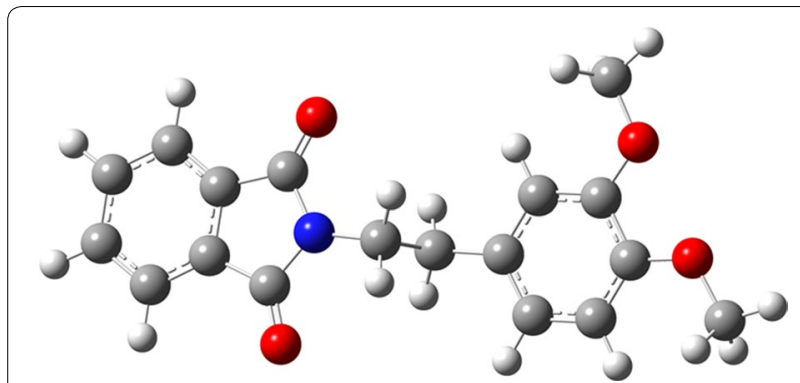

Fig. 4 Optimized structure of 2-(2-(3,4-dimethoxyphenyl)ethyl) isoindoline-1,3-dione (B3LYP/6-311G, gas phase) form $R_{4}^{4}$ (33) rings that develop the second dimension in the $b c$ plane (Fig. 5). The propagation of $\pi$-stacking interactions between the dione $(C g 1=\mathrm{C} 1 / \mathrm{N} 2 / \mathrm{C} 3 / \mathrm{C} 8 /$ C9) and fused benzene $(\mathrm{Cg} 2=\mathrm{C} 4-\mathrm{C} 9)$ rings results in $\mathrm{Cg} 1 \cdots \mathrm{Cg} 2^{\mathrm{iii}}$ stacking (symmetry code $\mathrm{iii}=1-\mathrm{x}, 2-\mathrm{y}$, $-\mathrm{z}$ ), which develops the third dimension along the direction of the $a$-axis (Fig. 6). The value of the intercentroid distance between the $C g 1$ and $C g 2$ rings (3.5364(14) $\AA$ ) is very close to the value of the interplanar distance (3.4485(10) $\AA$ ), corresponding to a face-to-face interaction [33], where the dione ring acts as the acceptor of electronic density and the benzene fused ring as the

Table 2 Geometric parameters of the intermolecular interactions of compound 1

\begin{tabular}{|c|c|c|c|c|c|}
\hline D-H...A & Symmetry code & D-H $(\AA)$ & $H \cdots A(\AA)$ & $D \cdots A(\AA ̊)$ & $D-H \cdots A\left({ }^{\circ}\right)$ \\
\hline $\mathrm{C} 16-\mathrm{H} 16 \cdots O 3^{i}$ & $x, y-1, z$ & 0.95 & 2.58 & $3.241(3)$ & 127 \\
\hline $\mathrm{C} 6-\mathrm{H} 6 \cdots \mathrm{O} 19^{\mathrm{ii}}$ & $x, y+1, z-1$ & 0.95 & 2.58 & $3.366(2)$ & 140 \\
\hline
\end{tabular}

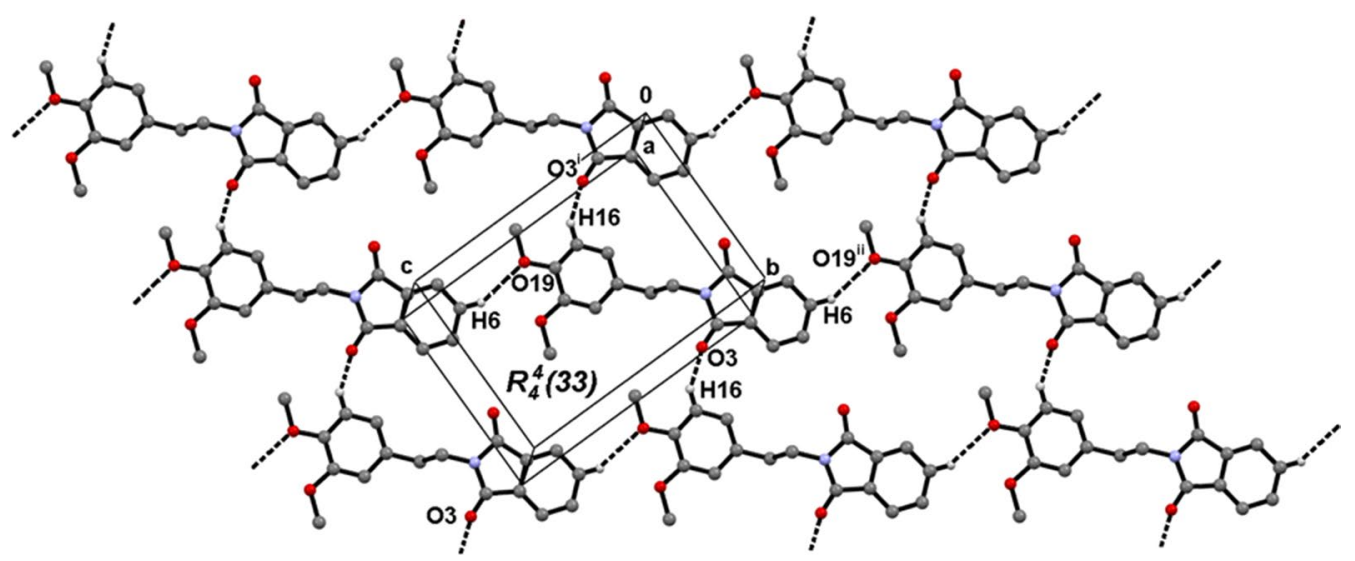

Fig. 5 Supramolecular structure of 1, based on $\mathrm{C} 16-\mathrm{H} 16 \cdots \mathrm{O} 3$ and $\mathrm{C} 6-\mathrm{H} 6 \cdots \mathrm{O} 19$ interactions. Viewed in the bc plane. Symmetry codes: (i) $x, y-1, \mathrm{z}$; (ii) $x, y+1, z-1$

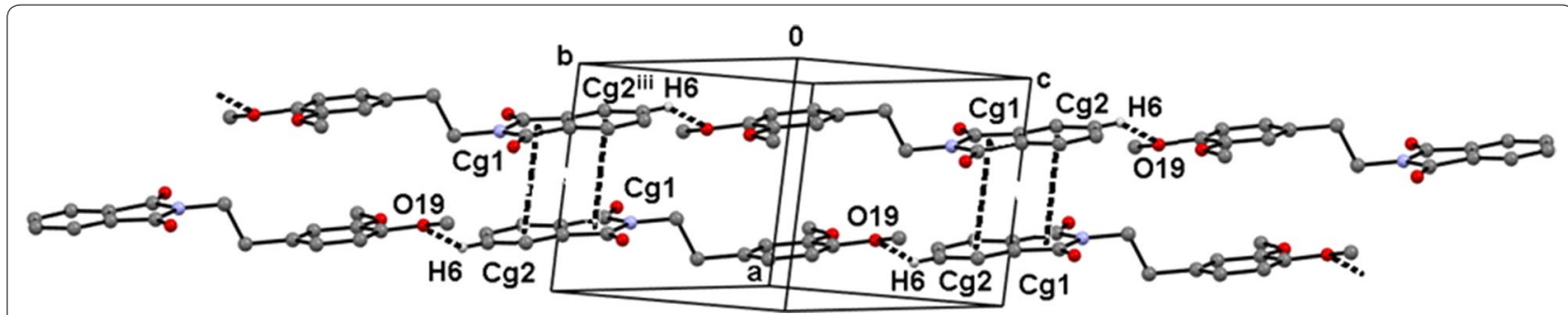

Fig. 6 The supramolecular 3D structure of compound 1 based on Cg1‥Cg2 interactions along the $a$-axis. Symmetry code: (iii) $-1-x, 2-y,-z$ 
donor. The C6-H6‥O19 interaction could be responsible for the non-negligible out of phenyl plane deviation of the methoxy group C19.

The absence of strong hydrogen bonding donors results in the participation of only one imide carbonyl in hydrogen bonding. The selective activation of one imide carbonyl group of the $N$-phenethylimides by Brønsted acids, such as $\mathrm{BBr}_{3}$ [34], TfOH [35] or organometallics [36], leads to regioselective intramolecular cyclization to deliver tetrahydroisoquinoline derivatives $[37,38]$. This selective regiochemical polarization could be involved in the mode of action of compound $\mathbf{1}$ as an AChEI, as previously proposed [39].

\section{In vitro experiments to determine $\mathrm{AChE}$ inhibition}

An in vitro assay was performed to examine the inhibitory effect of the crystallized compound on AChE. The test compound behaves as a competitive inhibitor (Fig. 7), with an inhibitory activity slightly weaker than that of neostigmine. Acute toxicity, examined in CD1 male mice by Lorke's method (Table 3), proved to be very low $\left(\mathrm{LD}_{50}>1600 \mathrm{mg} / \mathrm{kg}\right)$ compared to other AChEIs approximately from 43 - to 3000 -fold less toxic that is the case of Neostigmine $\mathrm{LD}_{50}=0.54 \pm 0.03 \mathrm{mg} / \mathrm{kg}$. The results clearly show that the synthesized compound has very low toxicity compared to the drugs currently on the market, which allows us to propose this molecule as a leader to generate a more potent family of drugs with a low toxicity unlike the drugs currently used for the treatment of AD that has many side effects. Due to the multiple undesirable effects of drugs currently employed to treat $\mathrm{AD}[1,2]$, the present values of 2-(2-(3,4-dimethoxyphenyl)ethyl)isoindoline-1,3-dione suggest the importance of future studies on this and other structurally related compounds to analyze their selectivity for and interactions with cholinesterases, and their potential therapeutic use in the treatment of $\operatorname{AD}[10,40]$.

\section{Conclusion}

In summary, the crystal of 2-(2-(3,4-dimethoxyphenyl) ethyl)isoindoline-1,3-dione was obtained and analyzed by $\mathrm{x}$-ray crystallography to determine its geometric structure, which was compared to the optimized structure predicted in the in silico experiment. No significant

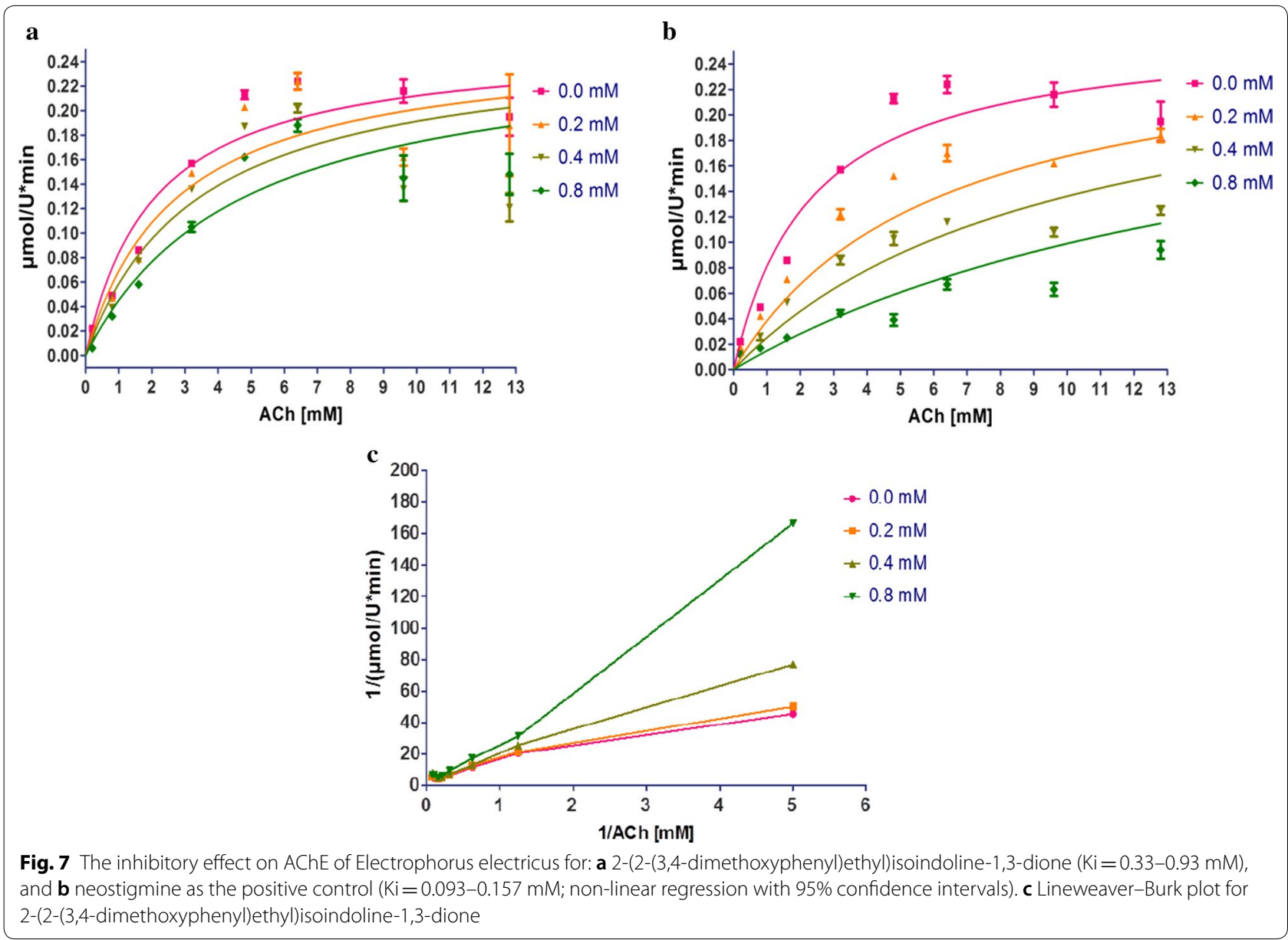


Table 3 Well-known AchE inhibitors with the respective $L_{50}$ in comparison with compound 1

\begin{tabular}{|c|c|c|}
\hline Inhibitors & Compound & $\mathrm{LD}_{50}$ (mice) \\
\hline & 1 & $>1600 \mathrm{mg} / \mathrm{kg}$ \\
\hline & Donepezil & 30 mg/kg [41] \\
\hline & Physostigmine & $3 \mathrm{mg} / \mathrm{kg}[42]$ \\
\hline & Neostigmine & $0.54 \pm 0.03 \mathrm{mg} / \mathrm{kg}[1]$ \\
\hline & Pyridostigmine & $37.5 \mathrm{mg} / \mathrm{kg}$ [41] \\
\hline
\end{tabular}

difference existed between these two structures (experimental and computational modeling) when comparing bond lengths or bond angles. Furthermore, an interesting crystalline network was formed by hydrogen bonding acceptors and soft-hydrogen bonding donors, as well as by dispersive $\pi-\pi$ interactions. Finally, an evaluation was made of the inhibitory effect of 2-(2-(3,4-dimethoxyphenyl)ethyl)isoindoline-1,3-dione on AChE, finding a competitive inhibition with a $\mathrm{Ki}$ of $330-930 \mu \mathrm{M}$ (95\% confidence interval). The acute toxicity is far less $\left(\mathrm{LD}_{50}>1600 \mathrm{mg} / \mathrm{kg}\right)$ than that of AChE inhibitors currently on the market almost 3000-fold less toxic than Neostigmine $\mathrm{LD}_{50}=0.54 \pm 0.03 \mathrm{mg} / \mathrm{kg}$. Therefore, future studies are needed to explore the inhibitory activity of this and related isoindoline-1,3-dione derivatives.

\section{Experimental}

\section{Instrumental}

All reagents and solvents were used as received from the commercial supplier (Sigma-Aldrich). All reactions were carried out in an oven-dried flask, agitating the mixtures with a stirring bar and concentrating them with a standard rotary evaporator. The melting point was measured in open-ended capillary tubes with a Stuart ${ }^{\circledR}$ SMP40 automatic melting point apparatus, and is uncorrected. Infrared (IR) spectra were obtained on a 100 FT-IR spectrometer (Perkin-Elmer) with a universal ATR accessory. Thin layer chromatography was performed on $0.25 \mathrm{~mm}$ thick silica gel 60 F254 plates (Merck, Darmstadt, Germany) and spots were detected under UV light. ${ }^{1} \mathrm{H}$ and ${ }^{13} \mathrm{C}$ nuclear magnetic resonance (NMR) spectra were recorded on a Varian Mercury 300 spectrometer $\left({ }^{1} \mathrm{H}\right.$, $300 \mathrm{MHz} ;{ }^{13} \mathrm{C}, 75 \mathrm{MHz}$ ) with tetramethylsilane (TMS) as internal reference. Chemical shifts $(\delta)$ are expressed in parts per million ( $\mathrm{ppm}$ ). Other parameters contemplated were the integration area, multiplicity ( $\mathrm{s}=$ singlet, $\mathrm{d}=$ doublet, $\mathrm{t}=$ triplet, $\mathrm{q}=$ quartet, $\mathrm{m}=$ multiplet), and coupling constant $(\mathrm{Hz})$. Electrospray ionization (ESI) high-resolution mass spectrometry was performed on a Bruker micrOTOf-Q-II instrument.

\section{Chemical synthesis and crystallization}

2-(2-(3,4-dimethoxyphenyl)ethyl)isoindoline-1,3-dione was synthesized by employing a reported procedure with slight modifications [43]. In brief, $491 \mathrm{mg}$ $(1.50 \mathrm{mmol})$ phthalic anhydride and $244 \mathrm{mg}(1.00 \mathrm{mmol})$ 
2-(3,4-dimethoxyphenyl)ethylamine were mixed and placed into a $50 \mathrm{~mL}$ round-bottom flask, then stirred and heated to gentle melting at $150-200{ }^{\circ} \mathrm{C}$ for $15-20 \mathrm{~min}$ until a dark-yellow color appeared. The reaction was cooled to room temperature and monitored by TLC (using ethyl acetate:hexane in an 8:2 proportion as eluent) before adding $40 \mathrm{~mL}$ ethyl acetate and sonicating the reaction to achieve complete dissolution. After the mixture was placed in a separation funnel, $50 \mathrm{~mL}$ of water ( $\mathrm{pH} 13)$ were added (three times) to eliminate the excess of phthalic anhydride. The ethyl acetate was recovered and enough $\mathrm{Na}_{2} \mathrm{SO}_{4}$ and activated carbon were added to be able to filter the mixture. Finally, the solvent was evaporated under a vacuum and the product was recrystallized four times in $\mathrm{CH}_{2} \mathrm{Cl}_{2}$ solution to obtain $0.301 \mathrm{~g}$ of colorless block-like crystals (suitable for X-ray) in $90 \%$ yield, m.p. $=171-172{ }^{\circ} \mathrm{C}$; IR $\left(\mathrm{ATR}, \mathrm{cm}^{-1}\right)$ v́: 3063 (C-H, Aromatic), 2943 (C-H, Aliphatic), $2842\left(\mathrm{O}-\mathrm{CH}_{3}\right.$, Aliphatic), $1705(\mathrm{C}=\mathrm{O}), 1600(\mathrm{C}=\mathrm{C}), 1466\left(\mathrm{CH}_{2}\right), 1427$ $\left(\mathrm{CH}_{3}\right), 1394(\mathrm{C}-\mathrm{N}), 1228\left(\mathrm{O}-\mathrm{CH}_{3}\right) .{ }^{1} \mathrm{H}$ NMR $\left(\mathrm{CDCl}_{3}\right.$, $300 \mathrm{MHz}) \delta 2.93$ (t, H-11), 3.90 (t, H-10), 3.80 (s, H-19), 3.83 (s, H-18), 6.78 (m, H-13,16,17), 7.70 (m, H-5,6), 7.82 (m, H-4,7); ${ }^{13} \mathrm{C}$ NMR $\left(\mathrm{CDCl}_{3}, 75 \mathrm{MHz}\right) \delta 168.2(\mathrm{C}-1,3)$, 123.19 (C-4,7), 132.0 (C-5,6), 130.4 (C-8,9), 39.3 (C-10), 34.0 (C-11), 133.9 (C-12), 111.1 (C-13), 148.7 (C-14), 147.6 (C-15), 111.8 (C-16), 120.8 (C-17), 55.7 (C-18,19). ESI $(\mathrm{m} / \mathrm{z}): 334.0956[\mathrm{M}+\mathrm{Na}][43]$.

\section{X-ray diffraction methods}

Single-crystal X-ray diffraction data was recorded on a D8 Quest CMOS (Bruker, Karlsruhe, Germany) area detector diffractometer with Mo $\mathrm{K} \alpha$ radiation, $\lambda=0.71073 \AA$. The structure was solved by using direct methods in the SHELXS97 [44] program of the WinGX package [45]. The final refinement was performed by the full-matrix least-squares method on $\mathrm{F}^{2}$ on the SHELXL97 program. $\mathrm{H}$ atoms on $\mathrm{C}$ were geometrically positioned and treated as riding atoms, with $\mathrm{C}-\mathrm{H}=0.93-0.98 \AA$, and $\operatorname{Uiso}(\mathrm{H})=1.5 \mathrm{Ueq}(\mathrm{C})$. The Mercury program was utilized for visualization, molecular graphics and analysis of crystal structures [46]. Material was prepared for publication with PLATON software [47]. The crystallographic data were deposited with the Cambridge Crystallographic Data Centre (CCDC) as supplementary publication CCDC number 1563664. Copies of the data can be obtained free of charge upon request from the CCDC, 12 Union Road, Cambridge CB2 1EZ, UK, (Fax: +44-01223-336033 or E-Mail: deposit@ccdc.cam.ac.uk).

Crystal data for $\mathrm{C}_{18} \mathrm{H}_{17} \mathrm{NO}_{4}(\mathrm{M}=311.3 \mathrm{~g} / \mathrm{mol})$ : triclinic, space group $\mathrm{P}-1$ (No. 2), $\mathrm{a}=7.4363(4) \AA$, $\mathrm{b}=8.7363(4) \quad \AA, \quad \mathrm{c}=12.1212(5) \quad \AA, \quad \alpha=89.573(2)$, $\beta=80.073(2), \gamma=74.650(2)^{\circ}, V=747.40(6) \AA^{3}, Z=2$,
$\mathrm{T}=163(2) \quad \mathrm{K}, \quad$ Dcalc $=1.38 \mathrm{~g} / \mathrm{cm}^{3}, \quad 16,483$ reflec tions measured $\left(2.4^{\circ} \leq 2 \Theta \leq 25.5^{\circ}\right)$, and 2750 unique (Rint $=0.088$, Rsigma $=0.0561)$ were used in all calculations. The final value of R1 was 0.049 (I $>2 \sigma(\mathrm{I}))$ and of wR2 0.135 (for all data), GooF $=1.058$ and Abs. coefficient $=0.098, \min / \max \left(\mathrm{e}^{-3}\right)$, and $\Delta \mathrm{F}=0.249 /-0.302$.

\section{Molecular modeling}

The optimization and vibrational frequency calculations were performed on Gaussian 09 software [48] with the DFT: B3LYP/6-311G basis set.

\section{In vitro experiments on AChE inhibition}

AChE inhibition was evaluated for compound 1 and a known inhibitor, neostigmine, employing the colorimetric method reported by Bonting and Featherstone [49], with a few modifications. This method determines the remaining amount of $\mathrm{ACh}$ by measuring the formation of hydroxamic acid from the choline ester after incubation with the enzyme. The color produced by the reaction with acid ferric chloride is related to enzymatic activity, the value of which was established by fitting the data to a typical curve (Fig. 7).

Briefly, Electrophorus electricus was the source of AChE (Sigma Chemical Co. C1682) for the assay. A mixture was made with $0.1 \mathrm{M}$ buffer $(\mathrm{pH} 8), 0.2$ units of AChE, and increasing concentrations of ACh iodide $(0.2,0.8,1.6,3.2,6.4,9.6$ and $12.8 \mathrm{mM})$ as the substrate for the enzymatic reaction, and 20 min later the alkaline hydroxylamine reagent was added. The test or reference compound was placed in the assay solution (at $0.2,0.4$ or $0.8 \mathrm{mM}$ ) and incubated with the enzyme for $20 \mathrm{~min}$ at $37^{\circ} \mathrm{C}$. Subsequently, addition was made of the alkaline hydroxylamine reagent and finally the $\mathrm{FeCl}_{3}$ reagent. The changes in absorbance at $540 \mathrm{~nm}$ were recorded following $10 \mathrm{~min}$ of incubation in a Benchmark BIO-RAD. To exclude interference due to the effects of the reference solution, the parameters were determined with the blank, which was the same volume of solution with the drugs, buffered reagents and the enzyme but without acetylthiocholine. The reaction rates were compared, and the inhibition in the presence of the test compounds was calculated. The Ki of each AChE-inhibitor was estimated by using a curve constructed with the steady-state enzyme inhibition constants.

\section{In vivo experiment (Lethal doses 50 ) on mice}

Briefly, three different groups of 3 (CD1 male mice 20-25 g) were formed, after that each group received one established concentration that was 10,100 and $1000 \mathrm{mg} /$ $\mathrm{kg}$ of our tested compound to determine a range of toxicity. They were observed by $24 \mathrm{~h}$, without presenting 
toxicity. After that we formed 3 new groups that were used to opening more of the dose spectrum based on first results, this was to probe new doses 1200, 1400 and $1600 \mathrm{mg} / \mathrm{kg}[50,51]$.

\section{Authors' contributions}

The chemical synthesis and spectroscopic analysis were carried out by EAJ and JBC; the NMR experiments and synthesis of the crystal structure were performed and analyzed by IIPM and FJMM; the interpretation of data was conducted by JGTF; in vitro experiments on AChE inhibition were carried out by MASU and EAJ. The paper was drafted by EAJ and IIPM. All authors participated in discussing the different versions of the manuscript. All authors read and approved the final manuscript.

\section{Author details}

${ }^{1}$ Laboratorio de Investigación en Bioquímica, Sección de Estudios de Posgrado e Investigación, Escuela Superior de Medicina del Instituto Politécnico Nacional, Plan de San Luis y Díaz Mirón s/n Casco de Santo Tomás, 11340 Mexico City, Mexico. ${ }^{2}$ Facultad de Ciencias Químicas, Universidad de Colima, Km. 9 Carretera Colima-Coquimatlán, C.P. 28400 Coquimatlán, Colima, Mexico. ${ }^{3}$ Laboratorio de Investigación en Fisiología, Sección de Estudios de Posgrado e Investigación, Escuela Superior de Medicina del Instituto Politécnico Nacional, Plan de San Luis y Díaz Mirón s/n Casco de Santo Tomás, 11340 Mexico City, Mexico. ${ }^{4}$ Laboratorio de Química Supramolecular y Nanociencias, Unidad Profesional Interdisciplinaria de Biotecnología del Instituto Politécnico Nacional, Av. Acueducto s/n Barrio la Laguna Ticomán, 07340 Mexico City, Mexico.

\section{Acknowledgements}

We are grateful to the Instituto Politécnico Nacional and CONACYT-Mexico.

\section{Competing interests}

All the authors declare that there is no competing interests related to the design of the study, the collection and analyses of data, the writing of the manuscript, or the decision to publish the results.

\section{Availability of data and materials}

The following is available for the checkCIF/PLATON report.

\section{Funding}

This work was supported by SIP m1930.

\section{Publisher's Note}

Springer Nature remains neutral with regard to jurisdictional claims in published maps and institutional affiliations.

Received: 14 May 2018 Accepted: 19 June 2018

Published online: 25 June 2018

\section{References}

1. Anand P, Singh B (2013) A review on cholinesterase inhibitors for Alzheimer's disease. Arch Pharm Res 36:375-399. https://doi.org/10.1007/s1227 2-013-0036-3

2. Bajda M, Więckowska A, Hebda M et al (2013) Structure-based search for new inhibitors of cholinesterases. Int J Mol Sci 14:5608-5632. https://doi. org/10.3390/ijms14035608

3. Zollo A, Allen Z, Rasmussen HF et al (2017) Sortilin-related receptor expression in human neural stem cells derived from Alzheimer's disease patients carrying the APOE epsilon 4 allele. Neural Plast 2017:1892612. https://doi.org/10.1155/2017/1892612

4. Rojas-Gutierrez E, Muñoz-Arenas G, Treviño S et al (2017) Alzheimer's disease and metabolic syndrome: a link from oxidative stress and inflammation to neurodegeneration. Synapse. https://doi.org/10.1002/syn.21990

5. Cermakova P, Nelson M, Secnik J et al (2017) Living alone with Alzheimer's disease: data from SveDem, the Swedish Dementia Registry. J Alzheimers Dis 58:1265-1272. https://doi.org/10.3233/JAD-170102

6. Czarnecka K, Szymański P, Girek M et al (2017) Tetrahydroacridine derivatives with fluorobenzoic acid moiety as multifunctional agents for Alzheimer's disease treatment. Bioorg Chem 72:315-322. https://doi. org/10.1016/j.bioorg.2017.05.003

7. Hamodat H, Cash MK, Fisk JD, Darvesh S (2017) Cholinesterases in normal and Alzheimer's disease primary olfactory gyrus. Neuropathol Appl Neurobiol. https://doi.org/10.1111/nan.12423

8. Cascella M, Bimonte S, Muzio MR et al (2017) The efficacy of epigallocatechin-3-gallate (green tea) in the treatment of Alzheimer's disease: an overview of pre-clinical studies and translational perspectives in clinical practice. Infect Agent Cancer 12:1-7. https://doi.org/10.1186/s1302 7-017-0145-6

9. Nwidu LL, Elmorsy E, Thornton J et al (2017) Anti-acetylcholinesterase activity and antioxidant properties of extracts and fractions of Carpolobia lutea. Pharm Biol 55:1875-1883. https://doi.org/10.1080/13880 209.2017.1339283

10. Kocyigit UM, Taslimi P, Gezegen H et al (2017) Evaluation of acetylcholinesterase and carbonic anhydrase inhibition profiles of 1,2,3,4,6-pentasubstituted-4-hydroxy-cyclohexanes. J Biochem Mol Toxicol. https://doi. org/10.1002/jbt.21938

11. Bhakta HK, Park CH, Yokozawa T et al (2017) Potential anti-cholinesterase and $\beta$-site amyloid precursor protein cleaving enzyme 1 inhibitory activities of cornuside and gallotannins from Cornus officinalis fruits. Arch Pharm Res 40:836-853. https://doi.org/10.1007/s12272-017-0924-z

12. Pisani L, Catto M, De Palma A et al (2017) Discovery of potent dual binding site acetylcholinesterase inhibitors via homo- and heterodimerization of coumarin-based moieties. ChemMedChem 12:1-11. https://doi. org/10.1002/cmdc.201700282

13. Parruca Sakata R, Figueiro M, Fabio Kawano D, Pereira Almeida W (2017) Effect on acetylcholinesterase and anti-oxidant activity of synthetic chalcones having a good predicted pharmacokinetic profile. Med Chem (Los Angeles) 13:1-10. https://doi.org/10.2174/1573406413666170525125730

14. Li F, Liu Y, Yuan Y et al (2017) Molecular interaction studies of acetylcholinesterase with potential acetylcholinesterase inhibitors from the root of Rhodiola crenulata using molecular docking and isothermal titration calorimetry methods. Int J Biol Macromol 104:527-532. https://doi. org/10.1016/j.ijbiomac.2017.06.066

15. Carvajal FJ, Inestrosa NC (2011) Interactions of AChE with A $\beta$ aggregates in Alzheimer's brain: therapeutic relevance of IDN 5706. Front Mol Neurosci 4:19. https://doi.org/10.3389/fnmol.2011.00019

16. Dinamarca MC, Arrázola M, Toledo E et al (2008) Release of acetylcholinesterase (AChE) from $\beta$-amyloid plaques assemblies improves the spatial memory impairments in APP-transgenic mice. Chem Biol Interact 175:142-149, https://doi.org/10.1016/j.cbi.2008.05.026

17. Ozadali-Sari K, Tüylü Küçükkılınç T, Ayazgok B et al (2017) Novel multitargeted agents for Alzheimer's disease: synthesis, biological evaluation, and molecular modeling of novel 2-[4-(4-substitutedpiperazin-1-yl)phenyl]benzimidazoles. Bioorg Chem 72:208-214. https://doi.org/10.1016/j. bioorg.2017.04.018

18. Ahmed HEA, Abdel-Salam HA, Shaker MA (2016) Synthesis, characterization, molecular modeling, and potential antimicrobial and anticancer activities of novel 2-aminoisoindoline-1,3-dione derivatives. Bioorg Chem 66:1-11. https://doi.org/10.1016/j.bioorg.2016.03.003

19. Shakir R, Muhi-Eldeen ZA, Matalka KZ, Qinna NA (2012) Analgesic and toxicity studies of aminoacetylenic isoindoline-1,3-dione derivatives. ISRN Pharmacol 2012:1-7. https://doi.org/10.5402/2012/657472

20. Kim HS, Kim Y, Doddareddy MR et al (2007) Design, synthesis, and biological evaluation of 1,3-dioxoisoindoline-5-carboxamide derivatives as T-type calcium channel blockers. Bioorg Med Chem Lett 17:476-481. https://doi.org/10.1016/j.bmcl.2006.10.042

21. Mary A, Renko DZ, Guillou C, Thal C (1998) Potent acetylcholinesterase inhibitors: design, synthesis, and structure-Activity relationships of bis-interacting ligands in the galanthamine series. Bioorg Med Chem 6:1835-1850. https://doi.org/10.1016/S0968-0896(98)00133-3

22. Zhao Q, Yang G, Mei X et al (2009) Novel acetylcholinesterase inhibitors: synthesis and structure-activity relationships of phthalimide alkyloxyphenyl N, N-dimethylcarbamate derivatives. Pestic Biochem Physiol 95:131-134. https://doi.org/10.1016/j.pestbp.2009.04.018

23. Alipour M, Khoobi M, Foroumadi A et al (2012) Novel coumarin derivatives bearing $N$-benzyl pyridinium moiety: potent and dual binding site acetylcholinesterase inhibitors. Bioorg Med Chem 20:7214-7222. https:// doi.org/10.1016/j.bmc.2012.08.052 
24. Si W, Zhang T, Zhang L et al (2016) Design, synthesis and bioactivity of novel phthalimide derivatives as acetylcholinesterase inhibitors. Bioorg Med Chem Lett 26:2380-2382. https://doi.org/10.1016/j. bmcl.2015.07.052

25. Musiał A, Bajda M, Malawska B (2007) Recent developments in cholinesterases inhibitors for Alzheimer's disease treatment. Curr Med Chem 14:2654-2679. https://doi.org/10.2174/092986707782023217

26. Panek D, Więckowska A, Wichur T et al (2017) Design, synthesis and biological evaluation of new phthalimide and saccharin derivatives with alicyclic amines targeting cholinesterases, beta-secretase and amyloid beta aggregation. Eur J Med Chem 125:676-695. https://doi.org/10.1016/j. ejmech.2016.09.078

27. Simoni E, Bartolini M, Abu IF et al (2017) Multitarget drug design strategy in Alzheimer's disease: focus on cholinergic transmission and amyloid- $\beta$ aggregation. Fut Med Chem 9:953-963. https://doi.org/10.4155/ fmc-2017-0039

28. Guzior N, Bajda M, Skrok M et al (2015) Development of multifunctional, heterodimeric isoindoline-1,3-dione derivatives as cholinesterase and $\beta$-amyloid aggregation inhibitors with neuroprotective properties. Eur J Med Chem 92:738-749. https://doi.org/10.1016/j.ejmech.2015.01.027

29. Hebda M, Bajda M, Więckowska A et al (2016) Synthesis, molecular modelling and biological evaluation of novel heterodimeric, multiple ligands targeting cholinesterases and amyloid beta. Molecules 21:1-24. https:// doi.org/10.3390/molecules21040410

30. Kiametis AS, Silva MA, Romeiro LAS et al (2017) Potential acetylcholinesterase inhibitors: molecular docking, molecular dynamics, and in silico prediction. J Mol Model 23:67-72. https://doi.org/10.1007/s0089 4-017-3228-9

31. Allen FH, Kennard O, Watson DG et al (1987) Tables of bond lengths determined by X-ray and neutron diffraction Part 1 Bond lengths in organic compounds. J Chem Soc Perkin Trans 2 213:S1. https://doi. org/10.1039/p298700000s1

32. Bernstein J, Davis RE, Shimoni L, Chang N-L (1995) Patterns in hydrogen bonding: functionality and graph set analysis in crystals. Angew Chemie Int Ed English 34:1555-1573. https://doi.org/10.1002/anie.199515551

33. García-Báez EV, Martínez-Martínez FJ, Höpf H, Padilla-Martínez II (2003) $\pi$-Stacking interactions and $\mathrm{C}-\mathrm{H} \cdots \mathrm{X}(\mathrm{X}=\mathrm{O}$, aryl) hydrogen bonding as directing features of the supramolecular self-association in 3-carboxy and 3-amido coumarin derivatives. Cryst Growth Des 3:35-45. https://doi. org/10.1021/cg0255826

34. Selvakumar J, Makriyannis A, Ramanathan CR (2010) An unusual reactivity of $\mathrm{BBr}(3)$ : accessing tetrahydroisoquinoline units from $\mathrm{N}$-phenethylimides. Org Biomol Chem 8:4056-4058. https://doi.org/10.1039/c0ob00269k

35. Selvakumar J, Rao RS, Srinivasapriyan V et al (2015) Synthesis of condensed tetrahydroisoquinoline class of alkaloids by employing $\mathrm{TfOH}$ mediated imide carbonyl activation. Eur J Org Chem 2015:2175-2188. https://doi.org/10.1002/ejoc.201403617

36. Maity AK, Roy S (2014) Multimetallic iridium-tin (Ir-Sn 3) catalyst in $\mathrm{N}$-acyliminium ion chemistry: synthesis of 3-substituted isoindolinones via intra- and intermolecular amidoalkylation reaction. Adv Synth Catal 356:2627-2642. https://doi.org/10.1002/adsc.201400234
37. Aranzamendi E, Sotomayor N, Lete E (2017) Phenolic activation in Chira Brønsted acid-catalyzed intramolecular a-amidoalkylation reactions for the synthesis of Fused isoquinolines. ACS Omega 2:2706-2718. https:// doi.org/10.1021/acsomega.7b00170

38. Pandey VK, Anbarasan P (2014) One-pot cascade trifluoromethylation/ cyclization of imides: synthesis of a-trifluoromethylated amine derivatives. J Org Chem 79:4154-4160. https://doi.org/10.1021/jo5002998

39. Bautista-Aguilera OM, Esteban G, Chioua M et al (2014) Multipotent cholinesterase/monoamine oxidase inhibitors for the treatment of Alzheimer's disease: design, synthesis, biochemical evaluation, ADMET, molecular modeling, and QSAR analysis of novel donepezil-pyridyl hybrids. Drug Des Devel Ther 8:1893-1910. https://doi.org/10.2147/ DDDT.S69258

40. Liu Z, Zhang A, Sun $\mathrm{H}$ et al (2017) Two decades of new drug discovery and development for Alzheimer's disease. RSC Adv 7:6046-6058. https:// doi.org/10.1039/C6RA26737H

41. Cayman Chemical (2015) Donepezil. In: Safety data sheets collection. vol 1, pp 1-5. https://www.caymanchem.com/msdss/13245m.pdf. Accessed 13 June 2018

42. Cayman Chemical (2016) Physostigmine. In: Safety data sheets collection. vol 1, pp 1-6. https://www.caymanchem.com/msdss/13027m.pdf. Accessed 13 June 2018

43. Andrade-Jorge E, Bahena-Herrera JR, Garcia-Gamez J et al (2017) Novel synthesis of isoindoline/isoindoline-1,3-dione derivatives under solventless conditions and evaluation with the human D2receptor. Med Chem Res 26:2420-2431. https://doi.org/10.1007/s00044-017-1942-6

44. Sheldrick GM (2008) A short history of SHELX. Acta Crystallogr Sect A Found Crystallogr 64:112-122. https://doi.org/10.1107/S01087673070439 30

45. Farrugia $L J$ (1999) WinGX suite for small-molecule single-crystal crystallography. J Appl Crystallogr 32:837-838. https://doi.org/10.1107/S0021 889899006020

46. Macrae CF, Edgington PR, McCabe P et al (2006) Mercury: visualization and analysis of crystal structures. J Appl Crystallogr 39:453-457. https:// doi.org/10.1107/S002188980600731X

47. Spek AL (2009) Structure validation in chemical crystallography. Acta Crystallogr Sect D Biol Crystallogr 65:148-155. https://doi.org/10.1107/ S090744490804362X

48. Frisch MJ, Trucks GW, Schlegel HB et al (2009) Gaussian 09, Revision E. 01. Gaussian, Wallingford

49. Bonting SL, Featherstone RM (1956) Ultramicro assay of the cholinesterases. Arch Biochem Biophys 61:89-98. https://doi.org/10.1016/00039861(56)90319-8

50. Chinedu E, Arome D, Ameh F (2013) A new method for determining acute toxicity in animal models. Toxicol Int 20:224. https://doi. org/10.4103/0971-6580.121674

51. Lorke D (1983) A new approach to practical acute toxicity testing. Arch Toxicol 54:275-287. https://doi.org/10.1007/BF01234480

\section{Submit your manuscript to a SpringerOpen ${ }^{\odot}$ journal and benefit from:}

- Convenient online submission

- Rigorous peer review

- Open access: articles freely available online

- High visibility within the field

Retaining the copyright to your article

Submit your next manuscript at springeropen.com 